Original Research Article

\title{
Prescribing pattern of drugs in sick newborn care unit in a tertiary care hospital, Haldwani, Uttarakhand, India
}

\author{
Pooja Agrawal*, Bhavana Srivastava, Sanjay Gaur, Renu Khanchandani, Bithorai Basumatary
}

Department of Pharmacology, Govt. Medical College, Haldwani, Uttarakhand, India

Received: 24 January 2017

Accepted: 25 February 2017

*Correspondence to:

Dr. Pooja Agrawal,

Email:

vijenderagrawal@yahoo.co.in

Copyright: (C) the author(s), publisher and licensee Medip Academy. This is an openaccess article distributed under the terms of the Creative Commons Attribution NonCommercial License, which permits unrestricted noncommercial use, distribution, and reproduction in any medium, provided the original work is properly cited

\begin{abstract}
Background: Sick Newborn Care Unit (SNCU) is meant to reduce the case fatality among sick newborns. Although it has been shown that patterns of drug utilization in SNCU are changing dynamically, current data on drug utilization patterns in SNCU is limited. This study was done to find out drug utilization pattern in newborn admitted at SNCU.

Methods: This prospective observational drug utilization study was carried out in SNCU of Government Medical College and Hospital, Haldwani (Uttrakhand). The pattern of drug use in 206 sick newborn admitted at SNCU was assessed.

Results: $75.25 \%$ sick newborns were in early neonatal period and $63.11 \%$ sick newborns were male. $33.98 \%$ sick newborn were preterm and mean \pm SD of weight of sick newborn was $2.16 \pm 0.6 \mathrm{~kg}$. Neonatal sepsis was commonest reason for admission followed by birth asphyxia. Three or more drugs (average 2.35drug/ Range 3-9 drug) were given to $52.91 \%$ new born and two drugs were given to $40.78 \%$ new born. Commonest route of drug administration was intravenous $(97.08 \%)$, followed by intramuscular $(72.82 \%)$, followed by orally $(13.59 \%)$ and $11.65 \%$ new born received drug by inhalation. Most frequently used drugs in SNCU were antibiotics (Ampicillin, Gentamicin, Amikacin, Cefotaxime). Only two adverse drug reactions (mild rash by ampicillin and fever) were reported during study period. Out of 206 sick newborn, 18.93\% died. Most common causes for death were respiratory distress syndrome $(41.03 \%)$ followed by sepsis $(23.08 \%)$ and hypoxic ischemic encephalopathy $(17.95 \%)$.
\end{abstract}

Conclusions: Antibiotics were of major concern in SNCU. The uncertainty regarding the choice of antibiotic can be minimized by periodic survey of etiological agent and their antibiotic susceptibility pattern.

Keywords: Adverse effects, Drug uses, Sick newborn care unit, Sick newborn

\section{INTRODUCTION}

The first 28 days of life is a vulnerable time for newborns with an estimated 2.8 million babies dying during the first month of life worldwide in 2013 . $^{1}$ The main causes of death include direct complications of prematurity $(36 \%)$, birth asphyxia (23\%), and infections $(23 \%){ }^{2}$ Highest risk of death or serious morbidity occurs among the 10 million born at term with low birth weight $(<2500 \mathrm{~g})$ and the 15 million born preterm (before 37 completed weeks of gestation) each year. ${ }^{3}$ Many lives could be saved, and morbidity prevented, through a combined health systems approach along the continuum of care, with identification of those at high risk and timely provision of quality inpatient and supportive care. ${ }^{4}$ Strengthening of existing facility based systems for the care of vulnerable newborns is the most effective approach for saving newborn lives and is central to achieving the goals of the Every Newborn Action Plan (ENAP). ${ }^{5}$ Although a combination of universal family-community care interventions has been shown to substantially reduce neonatal deaths in a developing country, the additional creation of a modern sick newborn care unit (SNCU) in a district hospital can additionally reduce neonatal mortality. ${ }^{6}$ SNCU are meant to reduce the case fatality among sick newborns, either born within the hospital or outside including home delivery. It also acts as the teaching and training hub for imparting the skills of newborn care. ${ }^{7}$ The use of drugs in newborns admitted to SNCU is characterized by a great variability in the management of the most common diseases and is a widespread phenomenon observed both within and 
between different countries. ${ }^{8}$ Although it has been shown that patterns of drug utilization in SNCU are changing dynamically; current data on drug utilization patterns in SNCU is limited.

\section{METHODS}

This prospective observational hospital based drug utilization study was carried out in sick newborns admitted in the SNCU of Dr. Susheela Tiwari Government Medical College and Hospital, Haldwani, Uttrakhand after approval from Institutional Ethics Committee. Written informed consent was obtained from all parents or guardian of the study participants. Data was collected from clinical notes of study participants from 01 September 2015 to 31 August 2016. All sick newborns of either sex admitted to SNCU for more than 24 hours were included in the study. Sick newborns not receiving any medications and only on fluids or electrolyte solution, parenteral nutrition, nutritional supplements, blood and blood products, oxygen, phototherapy, vaccinations or ophthalmic prophylaxis were not included in study.

Sick newborns that were discharged or died within 24 hours of SNCU admission were also not included in study. A suitable case record form was designed to collect the all necessary and relevant information. Case record form included the demographic details of patients and information on drug therapy (details of drugs used including its dose, frequency, route of administration and duration of treatment). Drugs prescribed was recorded in detail regarding indication, route of administration, trade or generic name, dose administered, frequency of administration, duration of administration and outcome, Vitals of the sick newborns were recorded wherever necessary. Information on adverse drug reactions (ADR) was obtained from the patient case record using ADR reporting form provided by $\mathrm{CDSCO}^{9}$ Descriptive statistics using SPS software was employed for analysis of data.

\section{RESULTS}

In present study, pattern of drug use in 206 sick newborn was assessed. There was a male predominance $(63.11 \%)$ in our study. Mode of delivery was caesarian section in $33.98 \%$ sick new born. Caesarian Section was more in female $(39.47 \%)$ in comparison to male $(30.77 \%)$, but difference was statistically insignificant. Place of delivery was PHC or CHC or Hospital in $94.20 \%$ sick new born. $75.25 \%$ sick newborn was admitted in early neonatal period (0-7 days). Percentage of male sick new born (76.92\%) was more in comparisons to female $(72.37 \%)$ in early neonatal period but difference were statistically insignificant. Mean age of sick newborn was 3.31 \pm 4.12 days. Majority of sick newborn were term (66. 02\%) followed by preterm (33.98\%).

Percentage of male preterm $(34.62 \%)$ was more in comparisons to female preterm $(32.90 \%)$ but difference were statistically insignificant. Mean birth weight of sick newborn was $2.16 \pm 0.6 \mathrm{Kg} .17 .48 \%$ sick newborn were very low birth weight, $33.01 \%$ were low birth weight, and $49.51 \%$ were having normal weight. Percentage of very low birth weight male $(18.46 \%)$ were more in comparisons to female very low birth weight $(15.79 \%)$. Similarly percentage of low birth weight male $(33.85 \%)$ were more in comparisons to female very low birth weight $(31.85 \%)$. However these differences were statistically insignificant.

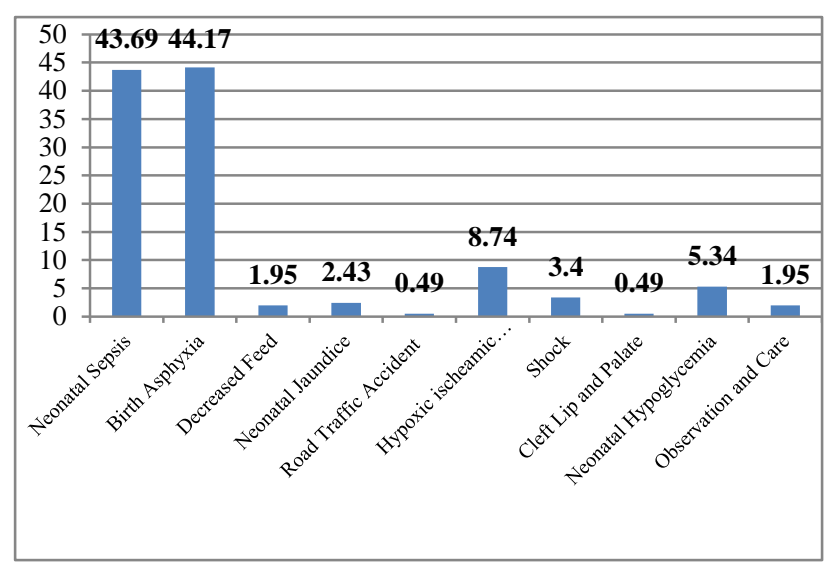

Figure 1: Distribution of sick newborn in SNCU according to cause of admission (percentages).

Birth asphyxia (44.17\%) was most common observed reason for admission to SNCU (Figure 1). Neonatal sepsis $(43.69 \%)$ was second most reason followed by hypoxic ischeamic encephalopathy $(08.74 \%)$, neonatal hypoglycemia $(05.34 \%)$, shock $(03.40 \%)$, neonatal jaundice $(02.43 \%)$, observation and care $(01.95 \%)$, decreased feed $(01.95 \%)$, road traffic accident $(0.49 \%)$, cleft lip and palate $(0.49 \%)$. More male was admitted due to birth asphyxia, neonatal sepsis, shock and neonatal hypoglycemia but differences were statistically insignificant.

Table 1: Distribution of sick newborn according to route of administration of drugs and sex.

\begin{tabular}{|c|c|c|c|}
\hline $\begin{array}{l}\text { Route of } \\
\text { administration } \\
\text { of drug }\end{array}$ & Male & Female & $\begin{array}{l}\text { Number } \\
\text { (percentage) }\end{array}$ \\
\hline Orally & $13(46.43)$ & $15(53.57)$ & $28(100.00)$ \\
\hline Inhalation & $17(70.83)$ & $07(29.17)$ & $24(100.00)$ \\
\hline Intramuscular & $97(64.66)$ & $53(35.33)$ & $150(100.00)$ \\
\hline Intravenous & $128(64.00)$ & $78(36.00)$ & $200(100.00)$ \\
\hline
\end{tabular}

Three or more drugs (average 2.35drug/ Range 3-9 drug) were given to $52.91 \%$ new born, two drugs were given to $40.78 \%$ new born and only $6.31 \%$ newborn received single drug. More male $(53.85 \%)$ received three or more drugs in comparison to female $(51.32 \%)$ but difference were statistically insignificant. Most common route of 
drug administration was intravenous (97.08\%), followed by intramuscular $(72.82 \%)$, followed by orally $(13.59 \%)$ and $11.65 \%$ new born received drug by inhalation (Table 1). More male (64.00) received drugs by IV in comparison to female $(36.00 \%)$ and these differences were statistically significant.

Antibiotics (93.20\%) was most commonly prescribed drug, followed by vasopressor (22.33\%), anti-epileptics (12.62\%), NSAIDs (12.14\%), mucolytics (09.22\%), steroids (5.34\%), antacid (5.34\%), micronutrients $(03.88 \%)$, bronchodilators $(03.88 \%)$, antiprotozoal agents $(03.88 \%)$,vitamins (1.94\%), and antifungal/ anticoagulant/ antiviral/ caffeine was prescribed to less than one percent sick new born (Figure 2).

Among the antibiotics ampicillin was most commonly prescribed antibiotics followed by gentamycin $(66.50 \%)$, amikacin (28.64\%), cefatoxime $(24.27 \%)$, Piper/Tazo (11.65\%), linezolid (07.77\%), and Vancomycin was given to $05.34 \%$ sick new born.

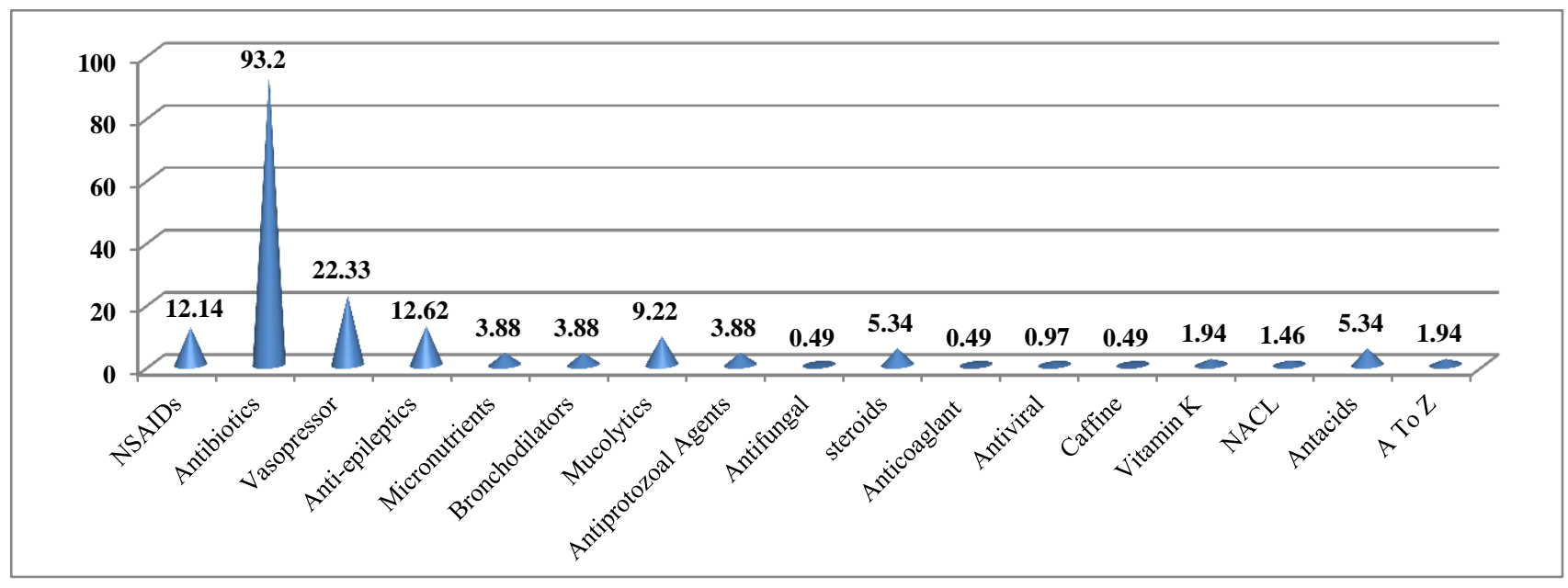

Figure 2: Distribution of sick newborn according drug use (percentages).

Table 2: Distribution of neonatal death according to various parameters.

\begin{tabular}{|c|c|c|}
\hline No. & Various parameters & $\begin{array}{l}\text { Number } \\
\text { (percentage } n=39 \text { ) }\end{array}$ \\
\hline \multirow[t]{3}{*}{1} & Age & \\
\hline & 0-7 days & $33(84.62)$ \\
\hline & 8-28 Days & $6(15.38)$ \\
\hline \multirow[t]{3}{*}{2} & Sex & \\
\hline & Male & $28(71.79)$ \\
\hline & Female & $11(28.21)$ \\
\hline \multirow[t]{3}{*}{3} & Place of Delivery & \\
\hline & Home & 03(07.69) \\
\hline & Hospital & $36(92.31)$ \\
\hline \multirow[t]{3}{*}{4} & Mode of Delivery & \\
\hline & Normal Vaginal & $25(64.10)$ \\
\hline & Cesarean Section & $14(35.90)$ \\
\hline \multirow[t]{3}{*}{5} & Period of gestation & \\
\hline & Term & $20(51.28)$ \\
\hline & Preterm & $19(48.71)$ \\
\hline \multirow[t]{4}{*}{6} & Birth weight & \\
\hline & Very Low Birth Weight & $16(41.02)$ \\
\hline & Low Birth Weight & $09(23.08)$ \\
\hline & Normal Birth weight & $14(35.90)$ \\
\hline
\end{tabular}

Only two adverse drug reactions (mild rash by ampicillin and fever) were reported during study period. Out of 206 sick newborn 135(65.54\%) were discharged, 24 (11.65\%) left against medical advice, 8(3.88) were discharged on request and 39 (18.93) died at SNCU. Out of 39 newborn deaths, $16(41.03 \%)$ died due to respiratory distress syndrome, $9(23.08 \%)$ due to sepsis, $3(07.69 \%)$ due to Congenital anomalies, $7(17.95 \%)$ due to hypoxic ischemic encephalopathy and $4(10.25 \%)$ due to hemorrhage. Out of 39 newborn deaths 28 (71.79\%) were male and $11(28.21 \% 0$ were female. Out of 39 newborn deaths $36(92.31 \%)$ were born in hospital. Out of 39 newborn deaths $25(64.10 \%)$ were born by normal vaginal delivery and $14(35.90 \%)$ by Cesarean Section. Out of 39 newborn deaths $20(51.28 \%)$ were full term, 16 $(41.02 \%)$ were very low birth weight, $09(23.08 \%)$ were low birth weight and $14(35.90 \%)$ were normal birth weight. Out of 39 newborn deaths $33(84.62 \%)$ were having age less than seven days (Table 2 ).

\section{DISCUSSION}

In present study, pattern of drug use in 206 sick newborn was assessed. There was a male predominance $(63.11 \%)$ in our study consistent with study done by Parkash et al in which $62.1 \%$ of patients were male. ${ }^{10}$ The gender discrimination in terms of access to health care is apparent in the study. There is immediate need to create 
awareness against gender discrimination which begins at the early age. ${ }^{11}$ In this study $75.25 \%$ sick newborn were admitted in early neonatal period. This is in accordance with study done by Butt et al in which patients admitted in early neonatal period were $83.4 \% .^{12}$ Mean age of sick newborn was $3.31 \pm 4.12$ days. A newborn is particularly vulnerable to adverse influences like asphyxia, infection, complications of preterm birth etc. during early neonatal days and requires special attention. Majority of sick newborn in this study were term $(66.02 \%)$ followed by preterm $(33.98 \%){ }^{13}$ In our study $17.48 \%$ sick newborn were very low birth weight, $33.01 \%$ were low birth weight, and $49.51 \%$ were having normal weight. In our study $76.09 \%$ preterm sick newborn were having low birth weight. Low birth weight (LBW) infants remain vulnerable to malnutrition, recurrent infections, neurodevelopmental disabilities and experience higher mortality. ${ }^{11}$

Birth asphyxia (44.17\%) was most common observed reason for admission to SNCU. Neonatal sepsis (43.69\%) was second most reason followed by hypoxic ischeamic encephalopathy $(08.74 \%)$, neonatal hypoglycemia $(05.34 \%)$, shock $(03.40 \%)$, neonatal jaundice $(02.43 \%)$, observation and care $(01.95 \%)$, decreased feed $(01.95 \%)$, road traffic accident $(0.49 \%)$, cleft lip and palate $(0.49 \%)$. More male was admitted due to birth asphyxia, neonatal sepsis, shock and neonatal hypoglycemia but differences were statistically insignificant.

Most frequently used drugs in NICU were antibiotics among which, Ampicillin, Gentamicin, Cefotaxime, Amikacin were commonly prescribed antibiotics. Few number of sick newborn received vasopressor agents, antiepileptic drugs, antiprotozoal agents and micronutrient compounds. Prescribing frequency of other drugs like bronchodilators, antifungals and anticoagulants was less than $1 \%$. Higher incidences of antibiotic exposure in SNCU could be due to common practice of prescribing antibiotics without waiting for outcome of bacterial culture results in neonates and may be due to seriousness of illness in neonates. However, inappropriate use of antibiotics leads to emergence of resistance. So antibiotic surveillance is mandatory to optimize antibiotic therapy especially in culture negative patients with infection like symptoms. ${ }^{14}$

In this study $93.20 \%$ of sick newborn received antibiotics and most of the sick newborn were prescribed at least two $(66.50 \%)$ antibiotics. Most commonly prescribed antibiotics were ampicillin $(67.48 \%)$, and gentamicin $(66.50 \%)$, amikacin $(28.64 \%)$ and cefatoxime $(24.27 \%)$. In study done by Uppal et al, $62 \%$ neonates received amikacin, $44 \%$ neonates received penicillin and $38 \%$ sick newborn received cefotaxime. ${ }^{15}$ Due to emerging resistance to ampicillin, combination of cephalosporin and aminoglycoside is recommended as the first line therapy. ${ }^{16}$ This was also evident from our study also. In study done by Choudhary et al, most frequently used antimicrobial agent was third generation cephalosporins. ${ }^{17}$ In study done by zaidi et al ampicillin and gentamicin for the treatment of neonatal sepsis may no longer be effective as $71 \%$ Klebsiella and $50 \%$ E. coli were reported resistant to gentamicin. ${ }^{18}$ However, selection of empirical antibiotic regimen is depend upon locally prevalent organism and their sensitivity/resistance pattern. So there is a need to formulate antibiotic policy in every hospital because the resistance of pathogenic microorganism to antimicrobial is increasing and it is difficult to keep pace with the development of resistance.

Three or more drugs (average 2.35drug/ Range 3-9 drug) were given to $52.91 \%$ new born, two drugs were given to $40.78 \%$ new born and only $6.31 \%$ newborn received single drug. In our study total encounters with an IV injection prescribed were $97.08 \%$. Similar findings were observed by Chatterjee et al in which intravenous route $(92.1 \%)$ was the commonest route of drug administration. ${ }^{19}$ Parenteral route is commonly seen in SNCU and it plays important role in management of sick neonates until they can tolerate enteral/oral feeding. ${ }^{20}$

Only two ADR (mild rash by ampicillin, fever) were reported during study period. The causality for both ADRs was "possible" category by WHO-UMC scale. They were mild in severity and preventable in nature. However neonates are potentially at significant risk for adverse drug reactions because of underdeveloped mechanisms and systems for handling drugs. ${ }^{21}$ It is probable that adverse drug reactions in neonates remain unrecognized or unreported. So there is a need to be vigilant regarding the adverse drug reaction and it must be doctor's responsibility.

Duration of stay was 3 to 5 days in SNCU in $54.61 \%$ neonates and in $26.61 \%$ of neonates range of stay was of 6-8 days. Mean \pm SD of length of stay in SNCU of all patients being admitted is $4.98 \pm 2.43$ days. Thus average length of stay at SNCU was less as compared to the previous studies could be due to death of neonates and discharge against medical advice. Out of 206 sick newborn 135 (65.54\%) were discharged, 24 (11.65\%) left against medical advice, 8 (3.88) were discharged on request and 39 (18.93) died at SNCU. Out of 39 newborn deaths $16(41.03 \%)$ died due to respiratory distress syndrome, $9(23.08 \%)$ due to sepsis, $3(07.69 \%)$ due to Congenital anomalies, $7(17.95 \%)$ due to hypoxic ischemic encephalopathy and $4(10.25 \%)$ due to hemorrhage. Increase in death rate at SNCU may be due to admission of neonates either from different hospitals or from neonates delivered at home especially with severe infections and morbidities. Precautionary measures like antenatal monitoring of high risk pregnancies, timely referral and resuscitation at the time of birth can reduce mortality. $^{22}$

\section{CONCLUSION}

Present study gave an overall pattern of drug use profile in a tertiary care SNCU and reflects the problems for 
which neonates were admitted in SNCU. The largest number of drugs per day was given in the first week in SNCU. Antibiotics were of major concern. The uncertainty regarding the choice of antibiotic can be minimized by periodic survey of etiological agent and their antibiotic susceptibility pattern. Similar studies done on larger scale and at regular intervals can reflect the changing pattern of drug prescribing which helps authority in planning to make necessary drugs available.

Funding: No funding sources

Conflict of interest: None declared

Ethical approval: The study was approved by the Institutional Ethics Committee

\section{REFERENCES}

1. UN-IGME. Levels and trends in child mortality: Report. New York, USA: UN-Interagency group for child mortality estimation; 2014. Available from: www.unicef.org/.../Levels_and_Trends_in_Child_Mo rtality_2014.pdf. Accessed on 03 Oct2016.

2. Lawn JE, Blencowe H, Oza S, You D, Lee AC, Waiswa $\mathrm{P}$ et al. Every Newborn: progress, priorities, and potential beyond survival. 2014;384(9938):189205.

3. Blencowe H, Cousens S, Oestergaard MZ, Chou D, Moller AB, Narwal R et al. National, regional, and worldwide estimates of preterm birth rates in the year 2010 with time trends since 1990 for selected countries: a systematic analysis and implications. 2012;379(9832):2162-72.

4. Bhutta ZA, Das JK, Bahl R, Lawn JE, Salam RA, Paul VK et al. Every Newborn. Can available interventions end preventable deaths in mothers, newborn babies, and stillbirths, and at what cost? 2014;384(9940):347-70.

5. WHO, UNICEF: Every Newborn: An action plan to end preventable newborn deaths Geneva: World Health Organization. 2014. Available from: http://www.who.int/maternal_child_adolescent/topics /newborn/every-newborn-action-plandraft.

6. Sen A, Mahalanabis D, Singh AK, Som TK, Bandyopadhyay S. Impact of a district level sick newborn care unit on neonatal mortality rate: 2-year follow-up. Journal of Perinatology. 2009;29:150-5.

7. UNDP. Sick newborn care unit. Available from: http://www.undp.org/content/dam/india/docs/NIPI/R esources_OtherPublications_BrochureSNCU.pdf; accessed on 01Dec 2015.

8. Jain S, Basu S, Parmar VR. Medication Errors In Neonates Admitted In Intensive Care Unit And Emergency Department. Indian J Med Sci. 2009;63(4):145-51.

9. Suspected adverse drug reaction reporting form for voluntary reporting of Adverse Drug Reactions by Healthcare Professionals. Available from:
http://www.cdsco.nic.in/writereaddata/ADRRF.pdf. Accessed on 12 Sept 2015.

10. Parkash J, Das N. Pattern of admissions to neonatal unit. J Coll Physicians Surg Pak. 2005;15(6):341-4.

11. Dhanraj G, Francis R, Srinivas R. Morbidity and mortality patterns of neonatal emergency in Gujarat Case study of GVK EMRI. Available from: URL: http://www.emri.in/images/stories/Morbidity\%20and $\% 20$ mortality\%20patterns.pdf.

12. Butt NA, Malik A, Kazi MY. Pattern of neonatal admissions in tertiary care hospital. Pak J Med Health Sci. 2010;4:436-38.

13. Adetokunbo OL, Barbara JS, Bale JR. Improving Birth Outcomes Meeting the Challenge in the Developing World Committee on, Board on Global Health, Institute of Medicine.2003. Available from: https://www.nap.edu/catalog/10841/improving-birthoutcomes-meeting-the-challenge-in-the-developingworld.

14. Stocker M, Ferrao E, Banya W, Cheong J, Macrae D, Furck A. Antibiotic surveillance on a pediatric intensive care unit: easy attainable strategy at low costs and resources. BMC Pediatr. 2012;12:196.

15. Uppal R, Chhabra A, Narang A. Pattern of Drug Use in Neonatal Intensive Care Unit. Indian Pediatr. 1998;35:647-9.

16. Jain NK, Jain VM, Maheshwari S. Clinical profile of neonatal sepsis. Kathmandu Univ Med J. 2003;1(2):117-20.

17. Choudhury HR, Hassan MA, Habibullah M. Neonatal sepsis and use of antibiotic in a tertiary care hospital. Pak J Med Sci. 2007;23(1):78-81.

18. Zaidi AK, Huskins WC, Thaver D, Bhutta ZA, Abbas Z, Goldmann DA. Hospital acquired neonatal infections in developing countries. 2005;365:117588 .

19. Chatterjee S, Mandal A. Drug utilization study in a neonatology unit of a tertiary care hospital in eastern India. Pharmacoepidemiol Drug Safety. 2007;10:1141.

20. Wafaa OC, Fahad AA. Neonatal TPN: Guidelines for making the process of ordering Parenteral Nutrition in NICU easier. $2^{\text {nd }}$ ed; 2007. Available from: URL: www.nutritioncare.org/About_ASPEN/Membership/. ../Neonatal_TPN/.

21. Fernandez A, Mondkar JA. Status of neonatal care units in India. J Postgrad Med. 1993;39(2):57-9.

22. Chishty AL, Iqbal A, Anjum A, Maqbool S. Spectrum of multiorgan systemic involvement in birth asphyxia. Pak J Pathol. 2001;12:81-7.

Cite this article as: Agrawal $\mathrm{P}$, Srivastava B, Gaur S, Khanchandani R, Basumatary B. Prescribing pattern of drugs in sick newborn care unit in a tertiary care hospital, Haldwani, Uttarakhand, India. Int J Basic Clin Pharmacol 2017;6:832-6. 